corriente con tintes nacionalistas, que recibió el Premio de Música del Movimiento Cubano por la Paz, con su obra Cantata de la paz, y el Premio de Música Coral, con Tríptico coral. Estas creaciones no sólo son representativas de un momento específico de la producción de Juan Blanco, también lo son de una característica siempre presente en su obra: la preocupación por los temas de la lucha contra la opresión y a favor de los derechos del hombre. Además de las mencionadas, otras composiciones son ejemplo de lo mismo, como: Imprecasiones por el crimen de Son My (1970); Chile vencerá, en solidaridad con los que luchaban en contra de la dictadura (1975); Música para un joven mártir, homenaje al alfabetizador mártir Conrado Benítez (1975); Ché dice a sus hijos y responden los niños cubanos (1977); 1789-1989, dedicada al bicentenario de la Revolución Francesa (1989), y muchas más.

En 1959, Juan Blanco fue nombrado director de la Banda del Estado Mayor del Ejército Rebelde, tarea que cumplió hasta 1961. También en 1959 conoció a Alejo Carpentier, quien despertó su interés por las vanguardias musicales y por la utilización de medios electroacústicos en la composición musical. Esta posibilidad técnica respondía a las necesidades estéticas de Blanco y lo sacaba de lo que él mismo llamó "un callejón sin salida". Abandonó, por lo tanto, la corriente nacionalista y se sumó al movimiento vanguardista musical cubano; además, el medio sociopolítico empujaba hacia los cambios en todos los ámbitos. En 1961 presentó sus primeras obras de música concreta y electrónica, iniciando un muy exitoso camino como creador. En 1964 ofreció el primer concierto realizado en Cuba de música electrónica y al año siguiente comenzó una serie de trabajos destinados a vincular la música electrónica con la actividad social: desfiles gimnásticos, sonorizaciones al aire libre, espectáculos multimedia, ambientaciones sonoras de exposiciones, monumentos, etc. En 1979 creó el primer laboratorio de música electroacústica de Cuba y más tarde impulsó encuentros internacionales de esa música, de gran significación. Además, fundó y dirigió el Taller de Música Electroacústica del ICAP (Instituto Cubano de Amistad de los Pueblos), donde formó numerosos compositores, siendo la experimentación sonora la línea matriz de esa entidad.

Es un sincero deseo que la muy breve síntesis hecha de la enorme y ejemplar labor realizada por Harold Gramatges y Juan Blanco sirva como un modesto y franco homenaje a dos grandes figuras de la música continental, así como de acicate para que ambos sean recordados permanentemente por quienes luchan en pro del desarrollo de la música americana.

Fernando García Facultad de Artes, Universidad de Chile,

Chile

fgarcia@uchile.cl

\title{
Lukas Foss; políglota y explorador (1923-2009)
}

Hace seis años, hablando del futuro, Lukas Foss expresó, con su espontaneidad característica, la esperanza de que "la justicia prevaleciera y mi música recibiese su merecida cuota” y, agregó, "creo que una gran parte de ésta es buena”. Este es un sueño que acarrea consigo mismo un creador toda su vida.

Hoy, a menos de dos semanas de yo cumplir 90 años $^{1}$, a los 86, murió Lukas al cabo de una vida activa, rica de experiencias, acompañada por Cornelia, su mujer y dos hijos, tres nietas y muchos colegas a quienes cautivó con su generosidad, sencillez y simpatía. Nació en Berlín y, a los 15 años, emigró con sus padres a Estados Unidos, huyendo del holocausto.

Copland, en alguna oportunidad, describió la obra de Lukas como compositor como "la más original y estimulante en América" y también la de un "saltarín", que transitaba entre todas las soluciones que le proveía la música contemporánea. Para Lukas éstas nunca constituyeron "soluciones" -ni siquiera "estilos"- sino técnicas que él necesitó para expresarse.

La primera de sus creaciones que escuché -esto antes de conocerle- fue la cantata The Prairie, obra basada en un poema de Carl Sandburg, que él consideraba -como otras compuestas antes de

${ }^{1}$ El maestro Juan Orrego-Salas nació el 18 de enero de 1919 (nota del Editor). 
1959- de su temprana juventud. Recuerdo que me impresionó por su apertura a cuantas técnicas se le ofrecían a un compositor en la primera mitad del siglo XX, sin perder contacto con la singularidad de lo que le motivaba expresar.

Muy pronto después, le conocí en un verano, en Tanglewood, donde él estudiaba dirección orquestal con Sergei Koussevitzky y yo composición con Aarón Copland. Su cordialidad e inteligencia nos conquistó de inmediato, a Carmen y a mí, y para nuestro hijo mayor, Juan Cristián, entonces apenas de 2 años, fue una permanente diversión. Lo tomaba en sus brazos y lo lanzaba al aire para recibirlo con contagiosas risotadas y, en nuestros descansos en el lago, le enseñaba a nadar. Con ese mismo espíritu espontáneo y jovial uno lo observaba actuar en el aula y en el escenario, a lo que agregaba sus siempre generosas referencias a sus colegas.

Su música no perdía profundidad con ese garbo. Un buen ejemplo es su A Parable of Death, para recitante, tenor solista, coro y orquesta, basada en la traducción al inglés del poema Märchen von Tod de Rilke, comisionada por la Orquesta Sinfónica de Louisville, que escuché unos años después. Lukas Foss ha destacado como la motivación fundamental que lo guió para componer esta obra, la interpretación que Rilke le confiere a la vida como "una secuencia de transformaciones en que la última es la muerte, el paso de un mundo externo a un mundo interior, que es el fruto de la vida".

En una declaración hecha a Robert Hines, Foss afirmó enfáticamente que esta obra la había escrito encontrándose en la cumbre de sus compromisos "con los ideales y procedimientos del neoclasicismo". De aquí en adelante, diría yo, "la secuencia de transformaciones" de que habla Rilke parece proyectarse en su creación como complemento enriquecedor de un lenguaje de esencia y perfiles ya bien establecidos.

De esta etapa surgen obras de gran valor, como su Time Cycle, sus Echoi, Variaciones barrocas, Paradigmas y muchas más. Es la época en que transita del tonalismo a la atonalidad, del serialismo a la improvisación dentro de parámetros establecidos, de la cita a las grafías.

Es el "saltarín" que Copland reconoce, expresándose en un lenguaje que, a pesar de su abundancia, no lo alejó de su propio y esencial espacio.

Juan Orrego-Salas Universidad de Indiana, Bloomington, Estados Unidos jucar@ciswired.com 